Dokuz Eylül Üniversitesi-Mühendislik Fakültesi Fen ve Mühendislik Dergisi

Cilt 20, Sayı 59, Mayıs, 2018
Dokuz Eylul University-Faculty of Engineering Journal of Science and Engineering Volume 20, Issue 59, May, 2018

DOI: $10.21205 /$ deufmd. 2018205940

\title{
Monte-Carlo simülasyonsuz-Uç Değer Modelleme ile Kompozit Bir Plakanın Belirsiz Titreşim Sınırlarının Belirlenmesi
}

\author{
Murat KARA ${ }^{1, *}$, Abdullah SEÇGIN ${ }^{2}$ \\ ${ }^{1}$ Dokuz Eylül Üniversitesi, Mühendislik Fakültesi, Makina Mühendisliği Bölümü, \\ 35397, İzmir(ORCID: https://orcid.org/0000-0001-5798-9014) \\ ${ }^{2}$ Dokuz Eylül Üniversitesi, Mühendislik Fakültesi, Makina Mühendisliği Bölümü, \\ 35397, İzmir(ORCID: https://orcid.org/0000-0002-1896-7629)
}

(Alınış / Received: 10.08.2017, Kabul / Accepted: 17.11.2017, Online Yayınlanma / Published Online: 15.05.2018)

Anahtar Kelimeler Özet: Belirsizliğe sahip titreșim sistemlerinde, cevap olasılıksal Belirsiz kompozit veya olasılıksal olmayan bazı simülasyon yöntemleri ile plaka, hesaplanabilmektedir. Monte Carlo simülasyonu bu amaçla en çok İstatistiksel moment Uç değer tabanlı modelleme, Monte Carlo simülasyonu kullanılan olasılıksal yöntemlerden biridir. Ancak bu yöntem ile istenilen belirsiz cevap fonksiyonunun eldesi yüksek örnekleme sayısı ve buna bağlı olarak uzun hesaplama süreleri gerektirmektedir. $\mathrm{Bu}$ çalışmada, çeşitli belirsiz plaka parametrelerine sahip simetrik katmanlı bir kompozit plakanın serbest ve zorlanmış titreşim cevabının sınırları bir Monte-Carlo simülasyonsuz-uç değer model kurularak elde edilmiștir. Kurulan model kompozit yapının diferansiyel denkleminin istatistiki çözümüne dayanmaktadır. Denklem çözücü olarak ayrık tekil konvolüsyon yöntemi başarı ile kullanılmıştır. Elde edilen sonuçlar Monte Carlo simülasyonları ile sinanarak, sunulan metodolojinin doğruluk ve çözüm süresi bağlamındaki verimi açıkça ortaya konmuştur.

\section{Determination of Uncertain Vibration Bounds of a Composite Plate via an Extreme Value Model-without Monte Carlo simulation}

Keywords

Uncertain composite plate, Statistical moment, Extreme value based modeling, Monte Carlo simulation
Abstract: In vibration systems having uncertainty, the response can be predicted via some probabilistic and non-probabilistic simulation techniques. Monte Carlo simulation is one of the most commonly used probabilistic techniques for this purpose. However, obtaining uncertain response function with this method requires large number of sampling, thus longer computation times. In this study, the bounds of free and forced vibration response of a symmetrically laminated composite plate with various uncertain plate parameters are estimated by constructing an extreme value model without Monte-Carlo simulation. As an equation solver, discrete singular convolution method is successfully used. Predicted results are tested by using conventional Monte-Carlo simulations to clearly show the efficiency regarding on the accuracy and the computation times of the proposed methodology. 
M. Kara vd. / Belirsiz Kompozit Bir Plakanın Titreşim Sınırlarının İstatistiksel Moment Tabanlı Bir Yaklaşım ve Uç Değer Model ile Tahmin Edilmesi

\section{Giriş}

Kompozit yapıların titreșim analizleri, genellikle birkaç deney sonucunda ortalama olarak belirlenmiş malzeme özellikleri ve yükleme koşulları altında yapılmaktadır. Belirlenen malzeme özellikleri yükleme ve sınır koşulları aynı hatta üretilen ürünlerde dahi küçük değişimler gösterebilir. $\mathrm{Bu}$ durum sistemin dinamik cevabında belirsizliğe neden olabilmektedir [1]. Belirsizlik, malzemenin değişkenliklerden, sönüm ve geometrideki küçük farklılıklardan, zorlama veya sınır koşullarının değişiminden kaynaklanan kontrol edilemeyen değişkenlikler olarak tanımlanır. $\mathrm{Bu}$ değişkenlikler özellikle yüksek frekanslı zorlamaya maruz yapılarda gözden kaçırılmamalıdır.

Özellikle son yıllarda, yapılardaki bu belirsizliklerin nicellenmesi (uncertainty quantification) ve yayınımının anlaşılabilmesi (uncertainty propagation) için pek çok çalışma yapılmaktadır. $\quad \mathrm{Bu}$ çalışmalarda "olasılıksal" ve "olasılıksal olmayan" başlıkları altında çeşitli yöntemler geliștirilmiştir. Olasılıksal yöntemler basit olarak, sistemin belirsiz girdi değişkenlerinin istatistiki dağılımı bilinirse, sistemin cevabı olasılık teorisi kullanılarak yine istatistiki olarak elde edilebilir kabulüne dayanmaktadır [2-6]. Monte Carlo simülasyonu bu amaçla, genellikle uygun bir analiz tekniği (sonlu elemanlar yöntemi, sonlu farklar yöntemi vb.) ile birlikte kullanılan en yaygın olasılıksal yöntemlerden biridir. Yöntemin başarısı örnekleme sayısı ile yakından ilgilidir. Ancak yüksek örnekleme sayısı yüksek hafıza ihtiyacı ve uzun hesaplama süreleri anlamına gelmektedir. $\mathrm{Bu}$ nedenle yine aynı yardımc analiz teknikleri ile birlikte kullanılabilen ve daha hızlı sonuç verme yeteneğine sahip "çokterimli (polinom) kaos açlımı (ÇKA)” yöntemi ilgi görmeye başlamıştır [5,6]. Bu yöntemde, belirsiz değişkenlerin dağılımı bir çokterimli olarak modellenir ve sistem cevabı yine benzer çokterimli katsaylları cinsinden ifade edilir. $\mathrm{Bu}$ yöntemde, dağılım tipi için uygun çokterimli tipi kullanılmaması durumunda hesaplama süreleri ve bunun yanında belirsizlik hesabındaki hata miktarı artmaktadır.

Bunun yanında daha az sayıda Monte Carlo simülasyonu kullanarak sınır değer tahmini yapabilen uç değer teorisi (UDT) tabanlı modelleme belirsiz titreşim problemlerinin sinırlarının belirlenmesinde başarı ile uygulanmıștır [7-11]. Bu çalıșmada, sözü edilen yöntemlere bir alternatif olarak, belirsiz yapıların diferansiyel denklemlerinin istatistiki olarak çözümleyebilen ve bu istatistiki cevapların sınır değerlerini tahmin edebilen Monte-Carlo simülasyonsuz bir uçdeğer model geliştirilmiştir. Önerilen yaklaşım sönüm, kalınlık ve özgül hacim gibi belirsiz parametrelere sahip simetrik katmanlı bir kompozit plakanın serbest ve zorlanmış titreşim sınırlarının tahmin edilmesi problemine uygulanmıştır. Sunulan metodoloji çözüm süresi ve hafiza ihtiyacı gibi kısıtlara sahip olan Monte Carlo simülasyon verilerine ihtiyaç duymamaktadır. Sunulan yöntemle elde edilen sonuçlar MonteCarlo yöntemi ile sınanarak tekniğinin kabiliyeti ortaya konulmuştur.

\section{Matematiksel Formülasyonlar}

\subsection{Simetrik katmanlı bir kompozit plakanın eğilme titreşimlerinin diferansiyel denklemi}

$\omega$ frekansına sahip harmonik noktasal bir dıș kuvvete maruz simetrik katmanlı bir kompozit plakanın eğilme titreşimlerinin diferansiyel denklemi şu şekilde ifade edilir [12]: 
M. Kara vd. / Belirsiz Kompozit Bir Plakanın Titreşim Sınırlarının İstatistiksel Moment Tabanlı Bir Yaklaşım ve Uç Değer Model ile Tahmin Edilmesi

$$
\begin{aligned}
& (1+1 \mathrm{j} \eta)\left\{D_{11} \frac{\partial^{4} w(x, y, t)}{\partial x^{4}}+4 D_{16} \frac{\partial^{4} w(x, y, t)}{\partial x^{3} \partial y}+\quad D_{m n}=\sum_{k=1}^{N} Q_{m n k}\left(\theta_{k}\right) \frac{h^{3}}{3}\left(\left(-\frac{1}{2}+\frac{k}{N}\right)^{3}\right.\right. \\
& \left.\begin{array}{c}
2\left(D_{12}+2 D_{66}\right) \frac{\partial^{4} w(x, y, t)}{\partial x^{2} \partial y^{2}}+4 D_{26} \frac{\partial^{4} w(x, y, t)}{\partial x \partial y^{3}} \\
\partial^{4} w(x, y)
\end{array}-\left(-\frac{1}{2}+\frac{(k-1)}{N}\right)^{3}\right), \quad(m, n=1,2,6)
\end{aligned}
$$

$\left.+D_{22} \frac{\partial^{4} w(x, y)}{\partial y^{4}}\right\}-\rho h \frac{\partial^{2} w(x, y, t)}{\partial t^{2}}$

$=F_{0} e^{j \omega t} \delta\left(x-x_{0}\right) \delta\left(y-y_{0}\right)$

Burada, $F_{0} \quad$ zorlamanın genliğini, $j=\sqrt{-1}, \mathrm{t} \delta\left(x-x_{0}\right) \delta\left(y-y_{0}\right)$, kuvvetin $\left(x_{0}, y_{0}\right) \quad$ uygulama konumundaki noktasallığını ifade eden Dirac-delta fonksiyonunu, $w$ eğilme titreşimini, $\eta$ plakanın yapısal sönümünü, $\rho$ plakanın birim alan için kütlesini, $h$ toplam kalınlığı, $\left(x_{0}, y_{0}\right)$ zorlama noktasını, $D_{11}$, $D_{12}, \quad D_{16}, \quad D_{26}$ ve $D_{66}$ kompozit plakanın eğilme rijitliklerini göstermektedir.

Eğilme rijitlikleri, plakanın orta noktasına göre her bir katmanın pozisyonunun bir fonksiyonu olarak yazılır [12]:

$$
D_{m n}=\sum_{k=1}^{N} Q_{m n k}\left(\theta_{k}\right) \frac{\left(h_{l}(k+1)\right)^{3}-\left(h_{l}(k)\right)^{3}}{3}
$$

Burada, $h_{l}(k) k$ katmanının orta eksene göre konumunu, $\theta_{k}$ ise $k$ katmanındaki fiber açısını, $Q_{m n k}$ ise $k$ katmanı için direngenlik matrisinden hesaplanan $Q$ matrisinin $(m, n)$ elemanıdır. $Q$ matrisinin hesaplanması için daha detaylı açıklamalar referans [12]'den alınabilir. Her bir katmandaki kalınlığın eşit olduğu kabulü yapılırsa, Denklem (2) plakanın toplam kalınlığı $(h)$ cinsinden şu şekilde yazılabilir:

Denklem (1) zaman bağımsız olarak, belirsiz sönüm $R^{\xi}=1+1 j \eta^{\xi}$, belirsiz kalınlık $h^{\xi}$ ve belirsiz özgül hacim $r_{\rho}^{\xi}=1 / \rho^{\xi}$ cinsinden $\xi$ rastgele dağılımlı olarak yeniden yazılırsa

$$
\begin{aligned}
& R^{\xi} r_{\rho}^{\xi}\left\{D_{11}^{h, \xi} \frac{\partial^{4} w^{\xi}(x, y)}{\partial x^{4}}+4 D_{16}^{h, \xi} \frac{\partial^{4} w(x, y)}{\partial x^{3} \partial y}\right. \\
& +2\left(D_{12}^{h, \xi}+2 D_{66}^{h, \xi}\right) \frac{\partial^{4} w^{\xi}(x, y)}{\partial x^{2} \partial y^{2}}+4 D_{26}^{h, \xi} \frac{\partial^{4} w^{\xi}(x, y)}{\partial x \partial y^{3}} \\
& \left.+D_{22}^{h, \xi} \frac{\partial^{4} w^{\xi}(x, y)}{\partial y^{4}}\right\}-\omega^{2} w^{\xi}(x, y) \\
& =\frac{r_{\rho}^{\xi}}{h^{\xi}} F_{0} \delta\left(x-x_{0}\right) \delta\left(y-y_{0}\right) .
\end{aligned}
$$

şeklinde stokastik (olasılıksal) diferansiyel denklem elde edilir. Burada $D_{i j}^{h, \xi}=D_{i j} / h^{\xi}$.

Basit mesnet sınır koşuluna sahip ince bir kompozit plaka için analitik doğal frekans $\left(\omega_{a n}\right)$,

$$
\begin{gathered}
\omega_{a n}=\left(\frac{D_{11}}{\rho h}\left(\frac{m \pi}{a}\right)^{4}+\frac{2 D_{12}}{\rho h}\left(\frac{m n \pi}{a b}\right)^{2}\right. \\
\left.+\frac{4 D_{66}}{\rho h}\left(\frac{m n \pi}{a b}\right)^{2}+\frac{D_{22}}{\rho h}\left(\frac{n \pi}{b}\right)^{4}\right)
\end{gathered}
$$

ile ifade edilir [13]. Burada, $a$ ve $b$ plakanın kenar uzunluklarını göstermektedir. Bir diş kuvvet altında, sistemin yerdeğiştirme cevabı ise mod süperpozisyon tekniği yardımıyla şu şekilde belirlenebilir:

$$
w(x, y)=\sum_{m=1}^{\infty} \sum_{n=1}^{\infty} W_{m n} \sin \left(\frac{m \pi}{a} x\right) \sin \left(\frac{n \pi}{b} y\right) .
$$


M. Kara vd. / Belirsiz Kompozit Bir Plakanın Titreşim Sınırlarının İstatistiksel Moment Tabanlı Bir Yaklaşım ve Uç Değer Model ile Tahmin Edilmesi

Burada, $m, n=1,2,3, \ldots$ ve

$$
\begin{gathered}
W_{m n}=\frac{\frac{4 \mathrm{~F}}{a b} \sin \left(\frac{m \pi}{a} x_{0}\right) \sin \left(\frac{n \pi}{b} y_{0}\right)}{(1+1 j \eta) \bar{D}-\rho h \omega^{2}}, \\
\bar{D}=D_{11}\left(\frac{m \pi}{a}\right)^{4}+2 D_{12}\left(\frac{m \pi}{a}\right)^{2}\left(\frac{n \pi}{b}\right)^{2} \\
+4 D_{66}\left(\frac{m \pi}{a}\right)^{2}\left(\frac{n \pi}{b}\right)^{2}+D_{22}\left(\frac{n \pi}{b}\right)^{4}
\end{gathered}
$$

2.2. Belirsiz değişkenlere sahip ince plakalar için Ayrık Tekil Konvolüsyon (DSC) Yöntemi

DSC tekniğinde, bir $W$ fonksiyonu ve onun $n$. dereceden türevi sayısal olarak şu şekilde ifade edilebilir [14,15]:

$$
W^{(n)}\left(R_{i_{r}}\right) \approx \sum_{k_{r}=-M_{r}}^{M_{r}} G_{k_{r}}^{(n)} W\left(R_{i_{r}+k_{r}}\right) .
$$

Burada, $i_{r}=0,1,2, \mathrm{~L}, N_{r}-1$ tamsayıları, $r$ : $x, y^{\prime}$ e göre yönleri, $R$ : x,y yönlerindeki $X$, $Y$ ayrık koordinatları, $N_{r}$ ve $M_{r}$ ise sırasıyla plakanın $r$ yönündeki yapısal ve yardımcı noktalarının sayısını göstermektedir. $G_{k_{r}}^{(n)}$ ise

$$
\begin{aligned}
G_{k_{r}}^{(n)}= & \frac{\mathrm{d}^{n}}{\mathrm{~d} r^{n}}\left(\frac{\sin \left[\pi / \Delta\left(R_{i_{r}}-R_{k_{r}}\right)\right]}{\pi / \Delta\left(R_{i_{r}}-R_{k_{r}}\right)}\right. \\
& \left.\cdot \exp \left(-\left(R_{i_{r}}-R_{k_{r}}\right)^{2} / 2 \kappa^{2}\right)\right),
\end{aligned}
$$

ile ifade edilir. Burada, $\Delta$ üniform dağılımlı ayrıklama (diskretizasyon) noktalarının arasındaki uzaklıktır.

Denklem (9), Denklem (4)'ün homojen formu (serbest titreşim analizi) için uygulanırsa, sınır koşullarının uygulanmasindan sonra $\left(N_{x}-2 \times N_{y}-2\right)$ boyutuna sahip bir matris denklem sistemi elde edilir:

$$
\begin{aligned}
& \left\{R ^ { \xi } r _ { \rho } ^ { \xi } \left(D_{11}^{h, \xi} \Gamma_{x}^{4} \otimes \mathrm{I}_{y}+4 D_{16}^{h, \xi} \Gamma_{x}^{3} \otimes \Gamma_{y}^{1}\right.\right. \\
& +2\left(D_{12}^{h, \xi}+2 D_{66}^{h, \xi}\right) \Gamma_{x}^{2} \otimes \Gamma_{y}^{2} \\
& \left.+4 D_{26}^{h, \xi} \Gamma_{x}^{1} \otimes \Gamma_{y}^{3}+D_{22}^{h, \xi} \mathrm{I}_{x} \otimes \Gamma_{y}^{4}\right) \\
& \left.-\left[\lambda_{n}^{\xi} \mathrm{I}_{x} \otimes \mathrm{I}_{y}\right]\right\} W^{\xi}(X, Y)=0
\end{aligned}
$$

Burada, $\lambda_{n}^{\xi}$ belirsiz özdeğerleri, $\Gamma_{r}^{(n)} n$. dereceden DSC karakteristik matrisini, $\mathrm{I}_{\mathrm{r}}$ birim matrisi ve $\otimes$ Kroneker çarpımı göstermektedir. $\mathrm{Bu}$ metodun detaylı uygulamaları için Referans [14,15] incelenebilir. Denklem (11) basit olarak şu şekilde gösterilebilir:

$\left\{Z_{11}\left[D_{x^{4}}^{4}\right]+4 Z_{16}\left[D_{x^{3} y}^{4}\right]+2\left(Z_{12}+2 Z_{66}\right)\left[D_{x^{2} y^{2}}^{4}\right]\right.$

$\left.+4 Z_{26}\left[D_{x y^{3}}^{4}\right]+Z_{22}\left[D_{y^{4}}^{4}\right]-\left[\omega_{n}^{2}\right]\right\} W=0$

Burada, $(i, j=1,2,6)$ için $\quad Z_{i j}=R^{\xi} r_{\rho}^{\xi} D_{i j}^{h, \xi}$, $\left[D_{x^{4}}^{4}\right]=\Gamma_{x}^{4} \otimes \mathrm{I}_{y}, \quad\left[D_{x^{3} y}^{4}\right]=\Gamma_{x}^{3} \otimes \Gamma_{y}^{1}$, $\left[D_{x^{2} y^{2}}^{4}\right]=\Gamma_{x}^{2} \otimes \Gamma_{y}^{2}, \quad\left[D_{x y^{3}}^{4}\right]=\Gamma_{x}^{1} \otimes \Gamma_{y}^{3} \quad$ ve $\left[D_{y^{4}}^{4}\right]=\mathrm{I}_{x} \otimes \Gamma_{y}^{4}{ }^{\prime}$ dır. $\quad$ Ayrica, $\quad\left[\omega_{n}^{2}\right]$, $\left(N_{x}-2\right) \cdot\left(N_{y}-2\right) \quad$ elemandan oluşan diyagonal bir matristir ve Denklem (12)'de $\quad \xi \quad$ sadelik amaciyla gösterilmemiştir.

\subsection{Rastgele değişkenli ince plakalar için istatistiksel moment ifadeleri}

$A$ ve $B$ istatistiksel değişkenlerin toplamlarının ve çarpımlarının varyansı şu şekilde tanımlanır [16]:

$$
\begin{array}{r}
\sigma^{2}\left(a_{1} \mathrm{~A} \mathrm{~m} b_{1} B\right)=a_{1}^{2} \sigma_{\mathrm{A}}^{2}+b_{1}^{2} \sigma_{\mathrm{B}}^{2} \\
m 2 a_{1} b_{1} \operatorname{cov}(\mathrm{A}, \mathrm{B}) \\
\sigma^{2}(\mathrm{~A} \cdot \mathrm{B})=\overline{\mathrm{A}}^{2} \sigma_{\mathrm{B}}^{2}+\overline{\mathrm{B}}^{2} \sigma_{\mathrm{A}}^{2}+\sigma_{\mathrm{A}}^{2} \cdot \sigma_{\mathrm{B}}^{2}
\end{array}
$$

Burada, $\sigma^{2}$ standart sapmanın $(\sigma)$ karesini yani varyansı, $a_{1}$ ve $b_{1}$ sabit sayıları, üst çizgi ise istatistiksel değişkenin ortalama değerini ve cov ise kovaryansı göstermektedir. Kovaryans 
M. Kara vd. / Belirsiz Kompozit Bir Plakanın Titreşim Sınırlarının İstatistiksel Moment Tabanlı Bir Yaklaşım ve Uç Değer Model ile Tahmin Edilmesi

$\operatorname{cov}(\mathrm{A}, \mathrm{B})=\overline{\mathrm{AB}}-\overline{\mathrm{A}} \overline{\mathrm{B}}$

olarak tanımlanır. Denklem

kullanılarak Denklem (12)'nin varyansı şu şekilde elde edilir:

$$
\begin{aligned}
& \sigma^{2}\left\{\left([T]-\omega_{n}^{2}[I]\right) W\right\}={\overline{\left([T]-\omega_{n}^{2}[I]\right)}}^{2} \sigma_{W}^{2} \\
& +\bar{W}^{2} \sigma_{\left([T]-\omega_{n}^{2}[I]\right)}^{2}+\sigma_{\left([T]-\omega_{n}^{2}[I]\right)}^{2} \sigma_{W}^{2}=0
\end{aligned}
$$

burada,

$$
\begin{aligned}
& {[T]=Z_{11}\left[D_{x^{4}}^{4}\right]+4 Z_{16}\left[D_{x^{3} y}^{4}\right]+2 Z_{12}\left[D_{x^{2} y^{2}}^{4}\right]} \\
& +4 Z_{66}\left[D_{x^{2} y^{2}}^{4}\right]+4 Z_{26}\left[D_{x y^{3}}^{4}\right]+Z_{22}\left[D_{y^{4}}^{4}\right] \cdot(17)
\end{aligned}
$$

Tüm istatistiki parametrelerin birbirlerinden bağımsız olduğu kabul edilirse, Denklem (16) aşağıdaki koşulların sağlanması ile çözülebilir:

i. $\overline{\left([T]-\left[\omega_{n}^{2}\right]\right)}=[\bar{T}]-\left[\overline{\omega_{n}^{2}}\right]=0$,

ii. $\sigma_{\left([T]-\left[\omega_{n}^{2}\right]\right)}^{2}=0$.

Denklem (18), ortalama doğal frekansların elde edilmesi amacıyla kolaylıkla çözülebilirken, Denklem (19), Denklem (13) yardımıyla aşağıdaki gibi yazılabilir:

$$
\begin{gathered}
\sigma_{\left([T]\left[\omega_{n}^{2}\right]\right)}^{2}=\sigma_{[T]}^{2}+[I]^{2} \sigma_{\omega_{n}^{2}}^{2} \\
-2[I] \operatorname{cov}\left([T], \omega_{n}^{2}\right) \\
\sigma_{[T]}^{2}=\left[D_{x^{4}}^{4}\right]^{2} \sigma_{z_{11}}^{2}+16\left[D_{x^{3} y}^{4}\right]^{2} \sigma_{Z_{16}}^{2} \\
+4\left[D_{x^{2} y^{2}}^{4}\right]^{2}\left(\sigma_{Z_{12}}^{2}+4 \sigma_{Z_{66}}^{2}\right) \\
+16\left[D_{x y^{3}}^{4}\right]^{2} \sigma_{Z_{26}}^{2}+\left[D_{y^{4}}^{4}\right]^{2} \sigma_{Z_{22}}^{2}
\end{gathered}
$$

ve $\sigma_{z_{i j}}^{2}$ ise Denklem (14) kullanılarak:

$$
\begin{aligned}
& \sigma_{z_{i j}}^{2}=D_{i j}^{2}\left(R^{2} \sigma_{r_{\rho}}^{2}+\sigma_{R}^{2} r_{\rho}^{2}+\sigma_{R}^{2} \sigma_{r_{\rho}}^{2}\right) \\
& \quad+\sigma_{D_{i j}}^{2}\left(R^{2} r_{\rho}^{2}+R^{2} \sigma_{r_{\rho}}^{2}+\sigma_{R}^{2} r_{\rho}^{2}+\sigma_{R}^{2} \sigma_{r_{\rho}}^{2}\right)
\end{aligned}
$$

olarak elde edilir. Doğal frekansların istatistiki parametreleri hesaplanırken, Denklem (22)'de sönüm katsayısı $(R)$ 'nin belirsiz olmadığı unutulmamalıdır. Tüm istatistiki parametrelerin bağımsız olduğu kabul edildiğinden (yani $\left.\operatorname{cov}\left([T], \omega_{n}^{2}\right)=0\right)$, Denklem (20)

$\sigma_{\left([T]-\left[\omega_{n}^{2}\right]\right)}^{2}=\sigma_{[T]}^{2}+[I]^{2} \sigma_{\omega_{n}^{2}}^{2}=0$,

şekline dönüşür. Denklem (23) ve Denklem (18) kullanılarak aşağıdaki eşitlik elde edilebilir;

$\left[\sigma_{\omega_{n}^{2}}^{2}\right]=\operatorname{eig}\left(\frac{\sigma_{[T]}^{2}}{[\overline{\bar{T}}]}\right)$.

Burada, eig(.) parantez içindeki ifadenin özdeğerlerini ifade eder. $\left[\sigma_{\omega_{n}^{2}}^{2}\right]$ matrisi ise doğal frekansların varyanslarının diyagonal elemanlar üzerinde bulunduran matristir. Denklem (24)'de hesaplanan değerler kullanılarak rezonans genliğindeki ve rezonans frekansındaki standart sapma değerleri şu şekilde hesaplanabilir:

$\left[\sigma^{2} W_{a}\right] \%\left[\overline{W_{a}^{2}}\right]=\left[\sigma_{\omega_{n}^{2}}^{2}\right] \%\left[\overline{\omega_{n}^{2}}\right]$,

${ }^{i} \sigma_{\omega^{2}}={ }^{p} \sigma_{\omega_{n}^{2}}$.

Burada $i, p$. tahrik edilen doğal frekansa tekabül eden bir tamsayıdır ve $\%$ ise eleman elemana bölümü gösteren bir semboldür.

\subsection{Uç değer tabanlı modelleme}

Uç değer teorisi (UDT) [17] bağımsız ve benzer olarak dağılımlanmış rastgele bir değişkenler dizisinin $U_{i}$, 
M. Kara vd. / Belirsiz Kompozit Bir Plakanın Titreşim Sınırlarının İstatistiksel Moment Tabanlı Bir Yaklaşım ve Uç Değer Model ile Tahmin Edilmesi

$V_{n}=\max \left\{U_{1}, U_{2}, \mathrm{~K} U_{n}\right\}$ özelliğine sahip $V_{n}$

değişkeninin istatistiki özelliklerini tanımlayan bir teoridir. Uç-değer analizinin önemli bir özelliği, bir rastgele değişkenin $V_{n}$ belirli bir sınır değerini $z(p)$ (quantile) aşma olasılığının p (exceedance probability) tahmin edilmesidir, yani $\operatorname{Pr}\left\{V_{n}>z(p)\right\}=p$ şeklinde formüle edilebilir (Burada $\mathrm{Pr}$ öngörülme fonksiyonudur). Stabil bir $V_{n}$ dağılımı üç asimptotik dağılım tiplerinden birine aittir. Bunlar Tip I: Gumbel dağılımı, Tip II: Fréchet dağılımı veya Tip III: Weibull dağılımıdır. EV modeli kurulmadan önce, verilerin Tip 1'e uygunluğu Hasofer Wang hipotezi testi [18] ile gösterilmelidir:

$$
H=\frac{k\left(\bar{U}-U_{k n}\right)^{2}}{(k-1)\left[\sum_{i=1}^{k}\left(\bar{U}-U_{i n}\right)^{2}\right]}
$$

Burada, $\bar{U}=\left(\sum_{j=1}^{k} U_{j n}\right) / k$ ile ifade edilir ve $U_{j n}$ verinin $\mathrm{n}$ örnekleminin azalan olarak sıralanmış j. terimidir. Bu test ile hesaplanan $H$ değeri Referans [19]'de verilen $H_{U}$ ve $H_{L}$ değerlerinin arasında olmalıdır.

Pratik bir sınır belirleme işlemi eşik aşma uç değer modeli kullanılarak oluşturulabilir. Sınır, $m$-gözlemsel geri dönüş düzeyi $u_{m}$ (m-Observational Return Level $u_{m}$ ) cinsinden verinin her bir $m$ gözleminin ortalama olarak belirlenen düzeyi geçtiği değer olarak belirlenir. Fiziksel bir sınırın var olduğu durumlarda elde edilecek olan sınır gerçek fiziksel sınırın bir yaklaşımıdır. Ancak fiziksel bir sınır yoksa rastgele belirsiz yapılar için belirli bir sınır aramak anlamlı değildir.

$\mathrm{Bu}$ durumlarda istatistiksel ölçüler belirlemek daha uygundur. Bir Tip 1 eşik modeli için $m$-gözlemsel geri dönüş düzeyi $u_{m}$ şu şekilde yazılabilir [20]:

$u_{m} \approx t \log \left(\frac{m k}{n}\right)+r$

Burada $m$ sınır tahminlemenin yapıldığ yığın boyutunu, $n$ modeli kalibre eden veri örnek boyutunu, $k$ en üst-derece istatistiği, $t$ ve $r$ ise model parametrelerini ifade etmektedir. Tip 1'e ait bir uç-değer modeli şu adımlarla kurulabilir:

1) Her bir modal veri için az sayıda veri örnekleminin kullanılması $(n<<m)$.

2) Optimum en üst derece istatistiğinin $k=1.5 \sqrt{n}$ ile hesaplanması.

3) Eşik değerinin $(r) k$. azalan en üst derece istatistiği olarak seçilmesi $\left(u_{k n}\right)$.

4) Modal parametre $(t)$ için maksimum olasılık belirleyicisinin hesaplanması:

$\hat{t}=1 / k \sum_{j=1}^{k} u_{j}-r$

Buna göre, Denklem (28)'de verilen sınır değeri tahminleyicisi şu şekilde yeniden yazılabilir:

$q(m)=\hat{t} \log \left(\frac{m k}{n}\right)+u_{k n}$.

Tahminleyici için yaklaşık güven aralığı şu şekilde elde edilebilir:

$t_{u_{m}}(\hat{q})=c_{n}\left[\zeta_{n}^{2} \frac{(k-1)}{k^{2}}+\frac{\pi^{2}}{6}-C_{k}\right]^{1 / 2}$.

Burada, $\zeta_{n}=\log (\mathrm{km} / \mathrm{n})$,

$c_{n}=\hat{q}(n e)-\hat{q}(n), \quad C_{k}=\sum_{n=1}^{k-1} n^{-2} \quad$ ve $e=2,718$ 'dir. 
M. Kara vd. / Belirsiz Kompozit Bir Plakanın Titreşim Sınırlarının İstatistiksel Moment Tabanlı Bir Yaklaşım ve Uç Değer Model ile Tahmin Edilmesi

\section{Sayısal Çalışmalar}

$\mathrm{Bu}$ bölümde, belirsiz plaka parametrelerine sahip $\{0,90,0,90,0\}$ yönsellikli, simetrik katmanlı bir kompozit plakanın serbest ve zorlanmış titreşimlerinin sınır değerlerinin bulunması amaçlanmıştır. Plakanın fiziksel ve mekanik özellikleri Tablo 1'de sunulmuştur. Tablo 1'de belirsiz değişkenlerin rastgele üretilmiş standart sapmaları da verilmiștir. Bu çalıșmada, tüm belirsiz değişkenlerin Normal dağılıma sahip olduğu kabul edilmiştir. Normal dağılım fiziksel parametrelere uygulandığından pozitif değerler olarak türetilmiștir.
$\mathrm{Bu}$ bölümde yapılan çalışmaları takip etmeyi kolaylaştırmak amacıyla siralarsak:

Bölüm 3.1: Doğrulama çalıșması için, kompozit plakanın doğal frekansları DSC yöntemi ile hesaplanmış ve analitik sonuçlar ile karşılaştırılmıştır. Burada DSC yöntemi ile farklı ayrıklama sayılarında doğal frekanslar hesaplanarak hata değeri-eleman sayısı bakımından en uygun ayrıklama sayısı elde edilmiştir. Ayrıca plakanın orta noktasindan $\quad\left(\left(x_{0}, y_{0}\right)=(0.5,0.5)\right)$ zorlama durumu için yine plakanın orta noktasının titreşim yerdeğiştirmefrekans cevabı analitik çözümler ile karşılaştırılarak doğrulama çalışması tamamlanmiștır.

Tablo 1. Plakanın fiziksel ve mekanik özelliklerinin ortalama ve standart sapmaları

\begin{tabular}{l|cc} 
Özellik & Ortalama & Standart sapma \\
\hline x yönündeki Young modülü $\left(E_{x}\right)[G P a]$ & 39 & 0 \\
y yönündeki Young modülü $\left(E_{y}\right)[G P a]$ & 8,6 & 0 \\
Kayma modülü $\left(G_{x y}\right)[G P a]$ & 3,8 & 0 \\
x yönündeki Poisson oranı $(v)$ & 0,28 & 0 \\
Özgül hacim $(1 / \rho)\left[m^{3} / \mathrm{kg}\right]$ & $4,762 \mathrm{E}-04$ & $2,381 \mathrm{E}-05$ \\
Kalınlık $(h)[m]$ & $5,00 \mathrm{E}-03$ & $5,00 \mathrm{E}-05$ \\
Kenar uzunlukları $(a, b)[m x \mathrm{~m}]$ & $1 \times 1$ & 0 \\
Yapısal sönüm $(\eta)$ & 0,02 & $6,00 \mathrm{E}-04$ \\
\hline
\end{tabular}

Bölüm 3.2: Belirsiz kalınlık ve özgül hacim parametrelerinden 200 örneklem türetilerek belirsiz plakanın doğal frekanslarının ortalama ve standart sapma değerleri Monte Carlo simülasyonu ile belirlenmiştir. Ayrıca doğal frekansların ortalamaları ve standart sapmaları sunulan yöntem ile hesaplanmıştır. Daha sonra hesaplanan ortalama ve standart sapma değerleri kullanılarak her bir mod için doğal frekanslar normal dağılıma uygun olarak türetilmiştir. Türetilen bu doğal frekanslar için bir uç değer tabanlı model kurulmuș ve doğal frekansların üst ve alt sınırları elde edilerek sonuçlar Monte Carlo simülasyonu ile karşılaştırılmıştır.

Bölüm 3.3: Bu bölümde ise, plakanın zorlama noktası titreșim yerdeğiștirme cevabının rezonans frekanslarındaki genliğinin ortalama ve standart sapma değerleri sunulan metodoloji ile elde edilmiştir. Daha sonra rezonans frekansındaki genlik değerleri yine, istatistiksel verilerin kullanılması ile türetilmiștir. Türetilen örneklemler yardımıyla bir uç değer modeli kurulmuş ve sonuçlar Monte Carlo simülasyonu ile karşılaştırılmıștır. 
M. Kara vd. / Belirsiz Kompozit Bir Plakanın Titreşim Sınırlarının İstatistiksel Moment Tabanlı Bir Yaklaşım ve Uç Değer Model ile Tahmin Edilmesi

\subsection{DSC yönteminin doğrulaması}

Bu bölümde, DSC yönteminin hassasiyeti analitik hesaplamalarla karşılaștırılarak gösterilmiştir. İlk olarak basit mesnet koşullarına sahip bir kompozit plakanın doğal frekansları farklı ayrıklama sayıları için hesaplanmış ve Denklem (5) ile elde edilen analitik sonuçlarla karşılaştırılarak \% hata değerleri bazı modlar için Tablo 2'de sunulmuștur. Burada doğal frekans hesaplamalarında yapının sönüm değeri DSC ile hesaplamalarda göz önüne alınmamıștır.

Tablo 2. Farklı ayrıklama sayıları için hesaplanan doğal frekanslar ve hata değerleri

\begin{tabular}{|c|c|c|c|c|c|c|c|c|c|}
\hline $\begin{array}{c}\text { Mod } \\
\text { Sayısı }\end{array}$ & Analitik & $\begin{array}{l}\mathrm{N}_{\mathrm{x}} \mathrm{xN} \\
11 \mathrm{x} 11\end{array}$ & $\begin{array}{c}\% \\
\text { Hata }\end{array}$ & $\begin{array}{l}\mathrm{N}_{\mathrm{x}} \mathrm{xN} \\
21 \mathrm{x} 21\end{array}$ & \% Hata & $\begin{array}{l}\mathrm{N}_{\mathrm{x}} \mathrm{xN} \\
31 \times 31\end{array}$ & \% Hata & $\begin{array}{l}\mathrm{N}_{\mathrm{x}} \mathrm{xN} \\
41 \mathrm{x} 41\end{array}$ & $\%$ Hata \\
\hline 1 & 12,953 & 12,999 & 0,357 & 12,953 & $2,1 \mathrm{E}-04$ & 12,953 & 1,7E-06 & 12,953 & $6,2 \mathrm{E}-08$ \\
\hline 2 & 29,546 & 29,557 & 0,038 & 29,546 & $1,2 \mathrm{E}-05$ & 29,546 & 8,1E-08 & 29,546 & $2,5 E-09$ \\
\hline 3 & 39,196 & 39,196 & 0,000 & 39,196 & $1,2 \mathrm{E}-05$ & 39,196 & $1,1 \mathrm{E}-07$ & 39,196 & 4,2E-09 \\
\hline 4 & 51,810 & 51,805 & 0,011 & 51,810 & $1,6 \mathrm{E}-05$ & 51,810 & $1,4 \mathrm{E}-07$ & 51,810 & 5,7E-09 \\
\hline 5 & 59,457 & 59,518 & 0,103 & 59,457 & $9,8 \mathrm{E}-06$ & 59,457 & 7,9E-08 & 59,457 & 3,1E-09 \\
\hline 6 & 78,003 & 78,042 & 0,050 & 78,003 & $3,1 \mathrm{E}-06$ & 78,003 & 2,9E-08 & 78,003 & $7,6 \mathrm{E}-10$ \\
\hline 7 & 84,101 & 84,186 & 0,102 & 84,101 & $4,9 \mathrm{E}-06$ & 84,101 & $4,0 \mathrm{E}-08$ & 84,101 & 1,9E-09 \\
\hline 8 & 94,652 & 94,725 & 0,077 & 94,652 & $1,1 \mathrm{E}-06$ & 94,652 & $8,0 \mathrm{E}-09$ & 94,652 & $7,2 \mathrm{E}-10$ \\
\hline 9 & 101,905 & 102,358 & 0,444 & 101,905 & $1,0 \mathrm{E}-06$ & 101,905 & $6,9 \mathrm{E}-09$ & 101,905 & $5,2 \mathrm{E}-10$ \\
\hline 10 & 116,573 & 116,663 & 0,077 & 116,573 & $2,6 \mathrm{E}-06$ & 116,573 & 2,1E-08 & 116,573 & 1,2E-09 \\
\hline 11 & 118,183 & 118,574 & 0,330 & 118,183 & $3,1 \mathrm{E}-06$ & 118,183 & 2,8E-08 & 118,183 & $8,1 \mathrm{E}-10$ \\
\hline 12 & 147,178 & 147,857 & 0,461 & 147,178 & $8,6 \mathrm{E}-07$ & 147,178 & 8,1E-09 & 147,178 & $8,4 \mathrm{E}-11$ \\
\hline 13 & 152,296 & 152,655 & 0,236 & 152,296 & $4,5 \mathrm{E}-07$ & 152,296 & 3,1E-09 & 152,296 & $3,7 \mathrm{E}-10$ \\
\hline 14 & 156,665 & 157,422 & 0,483 & 156,665 & $1,5 \mathrm{E}-06$ & 156,665 & 1,1E-08 & 156,665 & $6,0 \mathrm{E}-10$ \\
\hline 15 & 156,782 & 159,539 & 1,759 & 156,782 & $1,8 \mathrm{E}-06$ & 156,782 & $1,6 \mathrm{E}-08$ & 156,782 & $3,8 \mathrm{E}-10$ \\
\hline 16 & 171,625 & 174,290 & 1,553 & 171,625 & $6,4 \mathrm{E}-07$ & 171,625 & $6,0 \mathrm{E}-09$ & 171,625 & $1,0 \mathrm{E}-10$ \\
\hline 17 & 175,878 & 176,475 & 0,339 & 175,878 & $6,1 \mathrm{E}-07$ & 175,878 & 5,7E-09 & 175,878 & $7,4 \mathrm{E}-11$ \\
\hline 18 & 202,228 & 204,590 & 1,168 & 202,228 & $8,9 \mathrm{E}-07$ & 202,228 & $6,9 \mathrm{E}-09$ & 202,228 & 4,1E-10 \\
\hline 19 & 207,241 & 207,975 & 0,354 & 207,241 & $1,0 \mathrm{E}-06$ & 207,241 & $9,0 \mathrm{E}-09$ & 207,241 & $2,1 \mathrm{E}-10$ \\
\hline 20 & 223,668 & 232,640 & 4,011 & 223,668 & $4,5 \mathrm{E}-07$ & 223,668 & $1,4 \mathrm{E}-09$ & 223,668 & $1,5 \mathrm{E}-10$ \\
\hline 30 & 316,537 & 339,297 & 7,190 & 316,537 & $2,5 \mathrm{E}-06$ & 316,537 & 1,8E-09 & 316,537 & $1,3 \mathrm{E}-11$ \\
\hline 40 & 407,620 & 462,269 & 13,407 & 407,621 & $3,0 \mathrm{E}-05$ & 407,620 & 2,4E-09 & 407,620 & $6,3 \mathrm{E}-11$ \\
\hline 50 & 497,948 & 569,305 & 14,330 & 497,949 & $2,9 \mathrm{E}-04$ & 497,948 & 1,2E-09 & 497,948 & $6,2 \mathrm{E}-11$ \\
\hline
\end{tabular}

Tablo 2'den açıkça görüldüğü gibi, özellikle yüksek ayrıklama nokta sayılarında, hesaplanan doğal frekanslar ile analitik sonuçlar birbirleriyle oldukça uyumludur. Bu sonuçlar incelendiğinde, $N_{x} \times N_{y}=21 \times 21$ ayriklama sayısının 1 $500 \mathrm{~Hz}$ inceleme aralığında oldukça yeterli olduğu görülmüş ve ilerleyen analizler için bu ayrıklama sayısı seçilmiștir. Ayrıca hesaplamalarda, DSC parametresi $\quad M_{r}=N_{r}-1 \quad$ olarak seçilmiştir.

Bir diğer doğrulama çalışması olarak plakanın orta noktasından zorlanması durumunda, zorlama noktasının titreşim 
M. Kara vd. / Belirsiz Kompozit Bir Plakanın Titreşim Sınırlarının İstatistiksel Moment Tabanlı Bir Yaklaşım ve Uç Değer Model ile Tahmin Edilmesi

yerdeğiştirme cevabı 1-500 Hz arası için belirlenmiş ve analitik sonuçlarla karşılaştırılmıştır (Şekil 1).
Şekil 1 incelendiğinde yine DSC yönteminin analitik sonuçlarla oldukça uyumlu sonuçlar verdiği görülmektedir.

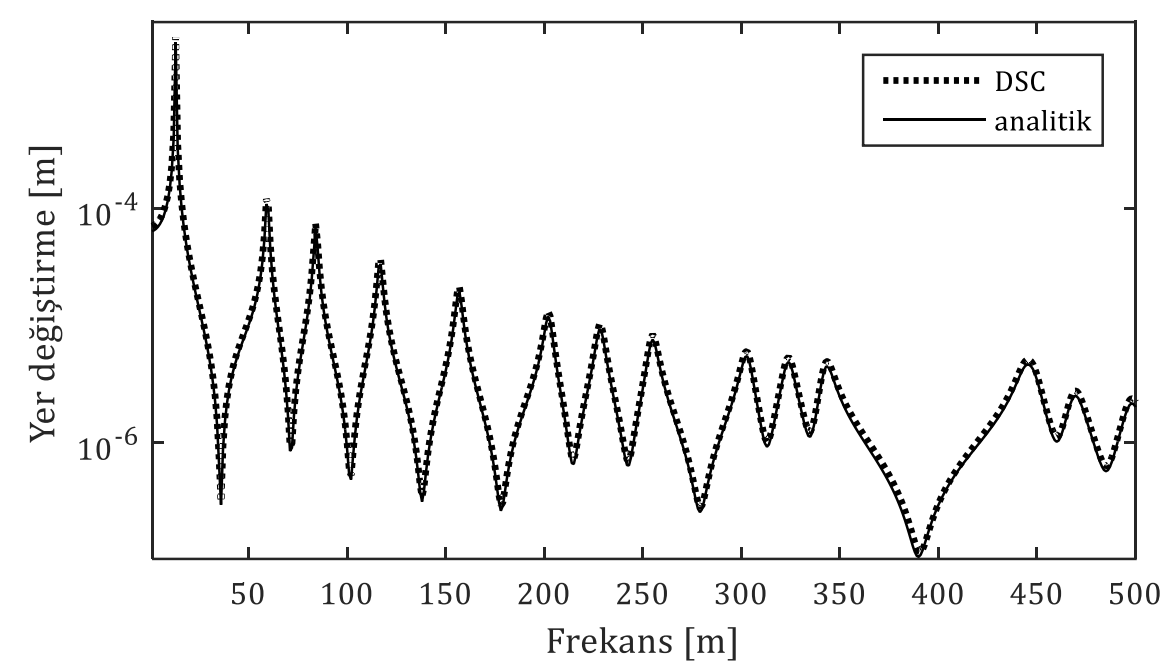

Şekil 1. Zorlama noktası yerdeğiştirme frekans cevabı

\subsection{Belirsiz Serbest Titreşim Analizi} 3.2.1. Doğal frekansların istatistiksel momentleri ve belirsizlik sinırlarının tayini

Bu bölümde, öncelikle belirsiz özgül hacim ve belirsiz kalınlığa sahip simetrik katmanlı bir kompozit plakanın doğal frekanslarının istatistiksel momentleri sunulan metodoloji ile elde edilmiş ve geleneksel Monte Carlo simülasyonu ile karşılaștırılmıștır. Monte Carlo simülasyonu için örneklemler normal dağılımın karakterini doğru bir șekilde ortaya koyma amaciyla iki standart sapma (\% 91 olasılık) ile türetilmiştir. Hesaplanan ortalama doğal frekanslar ve standart sapmaları Tablo 3'de sunulmuştur. Tablo 3'den görüldüğü gibi, sunulan yaklaşımın sonuçları Monte Carlo simülasyonu ile elde edilen sonuçlarla oldukça uyumludur.

Belirsiz doğal frekansların sınırlarının tahmini için elde edilen doğal frekans istatistiksel momentleri (ortalama ve standart sapma) kullanılarak Normal dağılıma göre her bir mod için 200 adet örneklem türetilmiştir. Türetilen örneklemler kurulan uç-değer modeline aktarılarak belirsiz doğal frekansların alt ve üst sınırları Denklem (30)'da verilen Weisman tahminleyicisi ile hesaplanmıștır. Uç değer modeli kurulmadan önce türetilen verilerin Bölüm 2.4'de belirtildiği gibi Tip 1'e uygunluğu çeşitli modlar (1., 5., 10., 30., 40. ve 50. modlar) için Hasofer-Wang testi ile onaylanmıștır (Şekil 2).

Şekil 3'de plakanın belirsiz doğal frekanslarının alt ve üst sınırları güvenlik sinırları ile birlikte Monte Carlo simülasyon sonuçları ile karşılaştırılmıştır. Monte Carlo simülasyonu 12,97 s'de tamamlanırken, önerilen teknik ile 0,65 s'de doğal frekansların alt ve üst sınırları, güvenlik sınırları ile birlikte hesaplanmıştır. Doğal frekansları alt sınırlarının belirlenmesi sırasında türetilen 200 adet doğal frekans örneklemi büyükten küçüğe göre 
M. Kara vd. / Belirsiz Kompozit Bir Plakanın Titreşim Sınırlarının İstatistiksel Moment Tabanlı Bir Yaklaşım ve Uç Değer Model ile Tahmin Edilmesi

yerine küçükten büyüğe göre sıralanmıştır.

Tablo 3. Doğal frekansların ortalama ve standart sapmalarının karşılaştırılması

\begin{tabular}{|c|c|c|c|c|}
\hline \multirow{2}{*}{$\begin{array}{c}\text { Mod } \\
\text { sayısı }\end{array}$} & \multicolumn{2}{|c|}{$\begin{array}{c}\text { Doğal frekansların } \\
\text { ortalamaları [Hz] }\end{array}$} & \multicolumn{2}{|c|}{$\begin{array}{l}\text { Doğal frekansların } \\
\text { standart sapmaları }\end{array}$} \\
\hline & $\begin{array}{l}\text { Sunulan } \\
\text { Metodoloji }\end{array}$ & $\begin{array}{c}\text { Monte } \\
\text { Carlo }\end{array}$ & $\begin{array}{l}\text { Sunulan } \\
\text { Metodoloji }\end{array}$ & $\begin{array}{c}\text { Monte } \\
\text { Carlo }\end{array}$ \\
\hline 1 & 12,9526 & 12,9316 & 0,4061 & 0,6198 \\
\hline 2 & 29,5458 & 29,4980 & 1,1310 & 1,4139 \\
\hline 3 & 39,1955 & 39,1321 & 1,6244 & 1,8757 \\
\hline 4 & 51,8102 & 51,7264 & 1,8034 & 2,4793 \\
\hline 5 & 59,4571 & 59,3609 & 2,4651 & 2,8453 \\
\hline 6 & 78,0034 & 77,8773 & 2,7474 & 3,7328 \\
\hline 7 & 84,1006 & 83,9646 & 3,6549 & 4,0246 \\
\hline 8 & 94,6519 & 94,4987 & 3,8515 & 4,5295 \\
\hline 9 & 101,9051 & 101,7403 & 4,2289 & 4,8766 \\
\hline 10 & 116,5731 & 116,3845 & 4,5238 & 5,5785 \\
\hline 11 & 118,1833 & 117,9922 & 4,5531 & 5,6556 \\
\hline 12 & 147,1778 & 146,9397 & 5,0412 & 7,0431 \\
\hline 13 & 152,2963 & 152,0499 & 6,4975 & 7,2880 \\
\hline 14 & 156,6650 & 156,4116 & 6,6746 & 7,4971 \\
\hline 15 & 156,7820 & 156,5284 & 6,8461 & 7,5027 \\
\hline 16 & 171,6247 & 171,3471 & 7,2134 & 8,2130 \\
\hline 17 & 175,8779 & 175,5934 & 7,4057 & 8,4165 \\
\hline 18 & 202,2277 & 201,9005 & 7,4470 & 9,6775 \\
\hline 19 & 207,2410 & 206,9058 & 7,6297 & 9,9174 \\
\hline 20 & 223,6683 & 223,3065 & 7,9953 & 10,7035 \\
\hline 30 & 316,5373 & 316,0253 & 12,0032 & 15,1477 \\
\hline 40 & 407,6206 & 406,9612 & 16,2302 & 19,5064 \\
\hline 50 & 497,9491 & 497,1436 & 20,6584 & 23,8290 \\
\hline
\end{tabular}



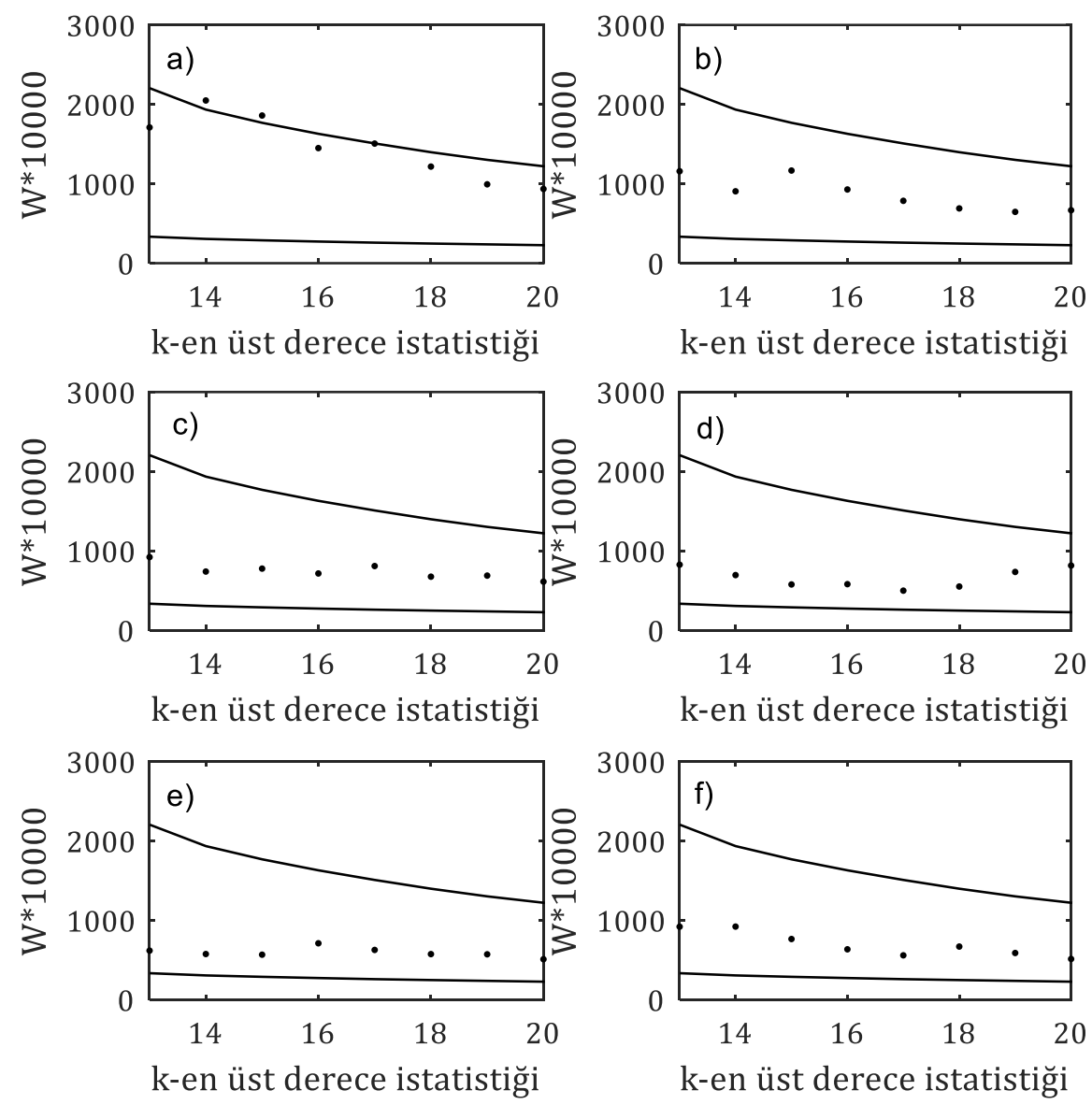

Şekil 2. Hasofer-Wang test sonuçları a) $\bmod 1$, b) $\bmod 5, c) \bmod 10$, d) $\bmod 30$, e) mod 40 ve f) mod 50 (çizgi: üst ve alt sınırlar, nokta: veri örnekleri). 

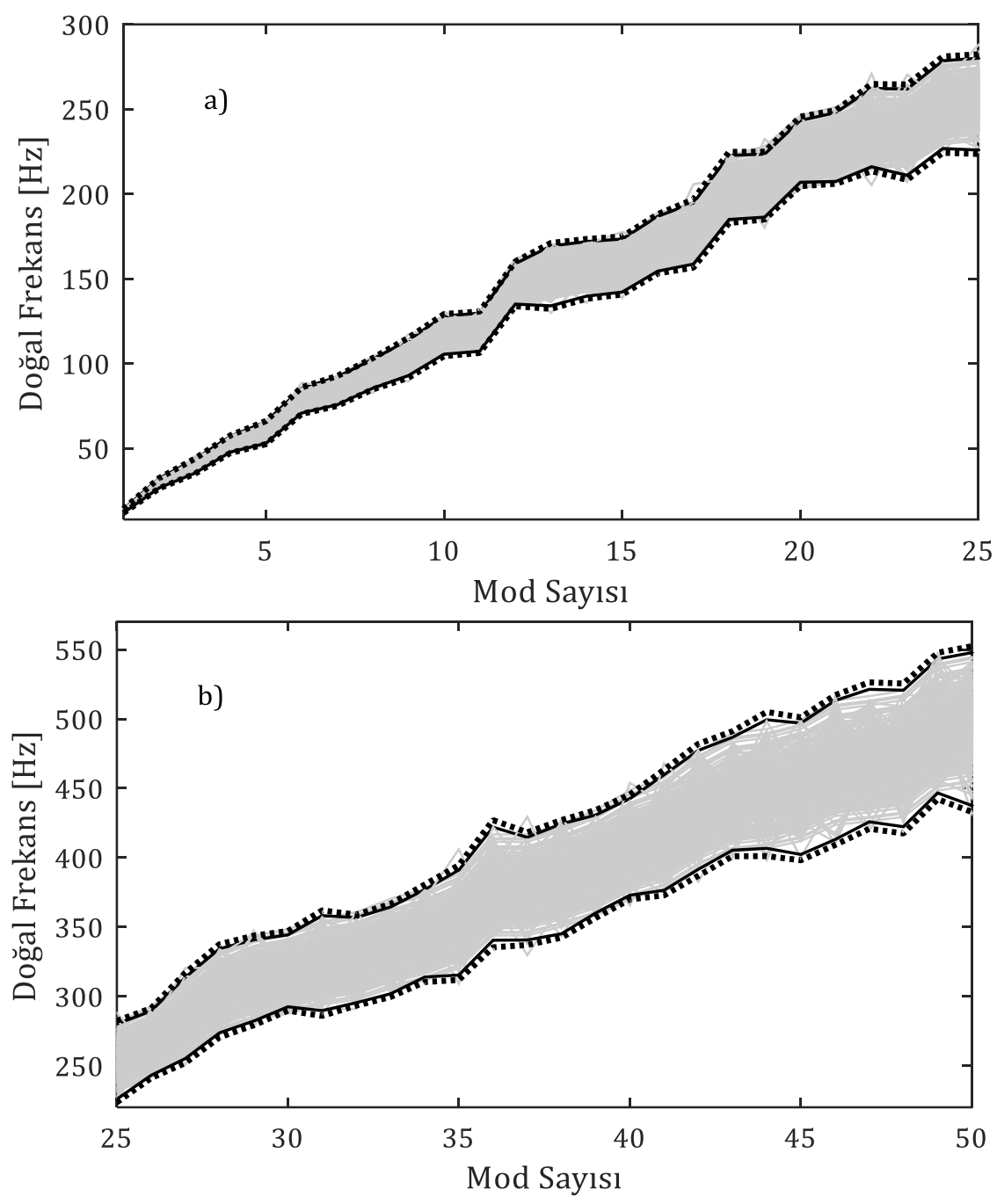

Şekil 3. Belirsiz doğal frekanslar ve sınırları a) 1-25. mod b) 26-50. mod (gri çizgiler: Monte Carlo simülasyonu, siyah çizgi: sunulan metodoloji ile elde edilen sınır değerleri, noktalı siyah: sunulan metodoloji ile elde edilen sınırların güvenlik sınırları)

Şekil 3 sunulan metodoloji ile elde edilen belirsiz doğal frekansların alt ve üst sinırlarının Monte Carlo simülasyonu yapmadan başarılı bir şekilde edilebildiğini açıça ortaya koymaktadır.

\subsection{Titreșim yerdeğiştirme cevap sinırlarının belirlenmesi}

$\mathrm{Bu}$ bölüm, belirsiz sönüm, kalınlık ve özgül hacme sahip plakanın orta noktasından zorlanması durumunda bu noktanın belirsiz cevap genliğinin üst sınır değerlerinin hesaplanmasını içermektedir. Denklem (25) ve (26) kullanılarak elde edilen istatistikler uç değer modeline gönderilerek orta nokta zorlamasında uyarılan rezonans frekanslarının ve buna karşıllı gelen rezonans genliklerinin sınırları elde edilmiştir. Uç değer modelin kurulması sirasinda Hasofer-Wang testi bu yeni 
M. Kara vd. / Belirsiz Kompozit Bir Plakanın Titreşim Sınırlarının İstatistiksel Moment Tabanlı Bir Yaklaşım ve Uç Değer Model ile Tahmin Edilmesi

veriler için tekrarlanmış fakat Bölüm 3.2.2'de elde edilen sonuçlar ile benzer sonuçlar elde edildiğinden bu bölümde sunulmamıștır. Sonuçlar Şekil 4'de Monte Carlo simülasyonu sonuçları ile birlikte gösterilmiştir. Elde edilen sınırların Monte Carlo verilerini hem düşük hem de yüksek frekanslarda oldukça güvenli şekilde sardığı açıkça görülmektedir. Bunun yanında Monte Carlo simülasyonu ile yapılan analizler 3342,2 saniyede tamamlanırken, kurulan metodoloji ile tahmin yalnızca 35,9 saniye sürmüştür. Sonuçlar irdelendiğinde ise yüksek frekanslı titreşimlerde belirsizliklerin cevap üzerinde daha etkili olduğu görülmektedir.
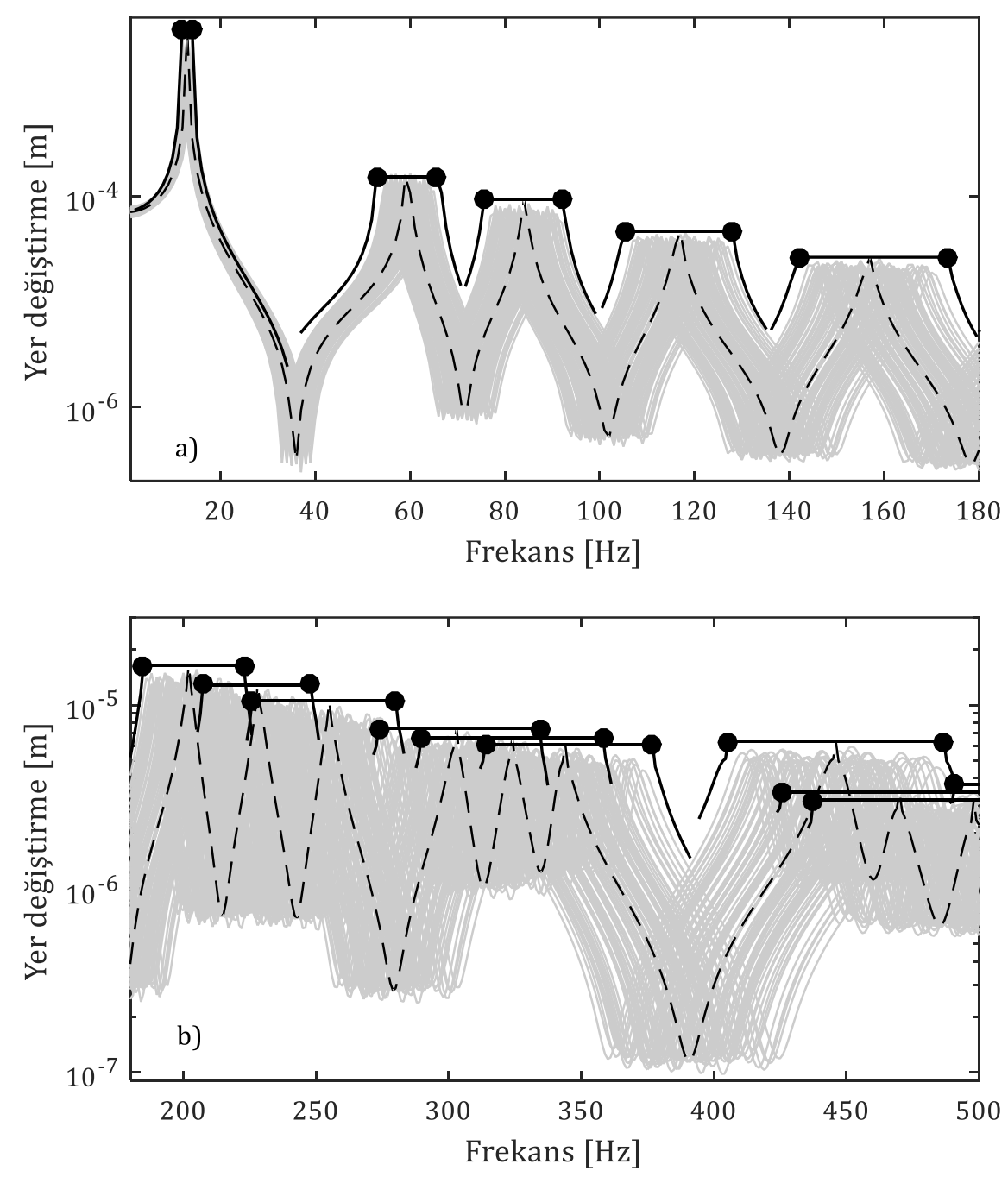

Şekil 4. Belirsiz deplasman frekans cevabı a) 1-180 Hz b) 180-500 Hz (gri: Monte Carlo simülasyonu, kesikli siyah: genliğin sınırı, $\bullet$ : frekans sınırı, siyah: genlik zarf eğrisi)

Sonuç olarak, istatistiksel momentler ve uç değer modeline dayalı olarak

geliştirilen ve bu çalışmada sunulan yaklaşım, belirsizliklerinin tahmininde 
M. Kara vd. / Belirsiz Kompozit Bir Plakanın Titreşim Sınırlarının İstatistiksel Moment Tabanlı Bir Yaklaşım ve Uç Değer Model ile Tahmin Edilmesi

Monte Carlo simülasyonuna oldukça güçlü bir alternatiftir.

\section{Tartışma ve Sonuç}

Bu çalışmada, sönüm, kalınlık ve özgül hacim belirsiz parametrelerine sahip simetrik katmanlı kompozit bir plakanın doğal frekanslarının ve titreșim yerdeğiştirme cevabının sınırlarının belirlenebilmesi için olasılıksal bir yaklașım geliştirilmiştir. $\mathrm{Bu}$ yaklaşım yüksek çözüm süresi ve hafıza kısıtlarına sahip Monte Carlo simülasyonuna ihtiyaç duymayan istatistiksel momentler ve uç değer modeline dayalı bir yaklaşımdır. Yöntem stokastik diferansiyel denklemin istatitistiki parametrelere göre ayrık tekil konvolüsyonu yöntemi ile başarılı bir şekilde elde edilmiştir. Yaklaşım sonucu elde edilen sonuçlar geleneksel Monte Carlo simülasyon sonuçları ile karşılaștırılarak, sunulan metodolojinin yetenekleri ortaya konmuştur. Bu sonuçlar önerilen tekniğin hesaplama süresi ve doğruluk açısından belirsizlik analizlerinde Monte Carlo simülasyonuna göre oldukça güçlü bir alternatif olarak kullanılabileceğini açıkça göstermiştir.

\section{Kaynakça}

[1] Fahy, F.J. 1994. Statistical Energy Analysis: A Critical Overview, Philosophical Transactions of the Royal Society of London A: Mathematical, Physical and Engineering Sciences, Cilt. 346, s. 431-447. doi:10.1098/rsta.1994.0027

[2] Evans, M., Swartz, T. 2000. Approximating Integrals via Monte Carlo and Deterministic Methods, OUP Oxford.

[3] Rubinstein, R.Y., Kroese, D.P. 2016. Simulation and the Monte Carlo Method, John Wiley \& Sons.

[4] Ghanem, R.G., Spanos, P.D. 2003. Stochastic Finite Elements: A
Spectral Approach, Courier Corporation.

[5] Sepahvand, K., Marburg, S., Hardtke, H.-J. 2007. Numerical solution of one-dimensional wave equation with stochastic parameters using generalized polynomial chaos expansion, Journal of Computational Acoustics, Cilt. 15, s. 579-593. doi:10.1142/S0218396X07003524

[6] Sepahvand, K., Marburg, S., Hardtke, H.-J. 2010. Uncertainty quantification in stochastic systems using polynomial chaos expansion, International Journal of Applied Mechanics, Cilt. 2, s. 305-353. doi:10.1142/S1758825110000524

[7] Dunne, L.W., Dunne JF. 2009 An FRF bounding method for randomly uncertain structures with or without coupling to an acoustic cavity, Journal of Sound and Vibration, Cilt. 322, s. 98-134. doi:10.1016/j.jsv.2008.10.035.

[8] Seçgin, A., Dunne JF, Zoghaib L. 2012. Extreme-Value-Based Statistical Bounding of Low, Mid, and High Frequency Responses of a Forced Plate With Random Boundary Conditions. Journal of Vibration and Acoustics, Cilt. 134 s. 21003. doi:10.1115/1.4005019.

[9] Seçgin, A. 2013. Modal and response bound predictions of uncertain rectangular composite plates based on an extreme value model. Journal of Sound and Vibration, Cilt. 332, s. 1306-23. doi:10.1016/j.jsv.2012.09.036.

[10] Seçgin, A. 2013. Bir uç-değer tabanlı modelleme ile belirsiz yapıların titreşim cevap sınırlarının tahmin edilmesi. Pamukkale Üniversitesi Mühendislik Bilim Dergisi, Cilt. 19, s.15-23.

[11]Seçgin, A., Kara M, Ozankan A. 2015 
M. Kara vd. / Belirsiz Kompozit Bir Plakanın Titreşim Sınırlarının İstatistiksel Moment Tabanlı Bir Yaklaşım ve Uç Değer Model ile Tahmin Edilmesi

Uç Değer Tabanlı Modelleme ile Belirsiz Kompozit Bir Plakanın Deneysel Titreşim Cevap Sınırlarının Tahmin Edilmesi. Uluslararası Katılımlı 17. Makina Teorisi Sempozyumu, İzmir, s. 4651.

[12]Ashton, J.E., Whitney, J.M. 1970. Theory of laminated plates, Technomic.

[13] Timoshenko S, Woinowsky-Krieger S. Theory of Plates and Shells. 2nd edition. New York: Mcgraw-Hill College; 1959.

[14]Seçgin, A., Sarıgül, A.S. 2008. Free vibration analysis of symmetrically laminated thin composite plates by using discrete singular convolution (DSC) approach: Algorithm and verification, Journal of Sound and Vibration, Cilt. 315, s. 197-211. doi:10.1016/j.jsv.2008.01.061

[15]Seçgin, A., Saide Sarıül, A. 2009. A novel scheme for the discrete prediction of high-frequency vibration response: Discrete singular convolution-mode superposition approach, Journal of Sound and Vibration, Cilt. 320, s. 1004-1022.

doi:10.1016/j.jsv.2008.08.031

[16]Goodman, L.A. 1960. On the Exact Variance of Products, Journal of the American Statistical Association, Cilt. 55, s. 708-713. doi:10.1080/01621459.1960.1048 3369

[17]Coles, S. 2001. Classical Extreme Value Theory and Models, ss. 4573. doi:10.1007/978-1-4471-36750_3

[18]Hasofer, A.M., Wang, Z. 1992. A Test for Extreme Value Domain of Attraction, Journal of the American Statistical Association, Cilt. 87, s. 171-177.

doi:10.1080/01621459.1992.1047
5189

[19]Hasofer, A.M. 1996. Non-parametric estimation of failure probabilities, Mathematical Models for Structural Reliability Analysis, CRC Press, Bölüm 4.

[20]Weissman, I. 1978. Estimation of Parameters and Large Quantiles Based on the k Largest Observations, Journal of the American Statistical Association, Cilt. 73, s. 812-815. doi:10.1080/01621459.1978.1048 0104 